\title{
Study on Financing Efficiency of China's Cultural Industry
}

\author{
Shihong Zeng \\ economics \& management school \\ Beijing university of technology \\ Beijing, China \\ zengshihong2000@aliyun.com
}

\author{
Mimi $\mathrm{Hu}$ \\ economics \& management school \\ Beijing university of technology \\ Beijing, China \\ humimi_314@163.com
}

\begin{abstract}
Based upon DEA model, this paper conducts an empirical study on the finance support efficiency of public companies from culture industry during the period from 2009 to 2012, and at the same time, by applying Logit model, analyses the factors that have impacts on the financing efficiency of culture industry. The results show that, the overall efficiency of cultural industry showed a rising trend, but the overall efficiency is not yet reached a high level, and there is more room to go. In addition, the Logit model results show that the factors influencing the financing efficiency of the cultural industry include firm size, asset utilization ability and etc. According to the analysis results of Logit model, this paper points out that the expansion of the scale of enterprises is critical at the moment to improve financing efficiency.
\end{abstract}

\section{Keywords-financing; efficiency; cultural Industry}

\section{INTRODUCTION}

With thirty years of reform and opening up, China's rapid economic development has attracted the world's attention, and China has become the second largest economy in the world. Looking at its development pattern, however, we can find out that China followed a rough development. In the period of economic transition, the government gradually realized the potential of culture as a "soft power" to develop the economy. As one kind of industrial models and economic forms, culture has great potential to develop, and at the same time, is the bridge which links economic base and superstructure. By developing its cultural industry, a country grows its economy and meanwhile expands its influence in the world. Therefore, the cultural industry is an advanced mode of economic development.

In recent years, the government gradually put it on the agenda to develop the cultural industry, and introduced various policies to encourage the development of cultural industry. In September 26, 2009, the State Council issued the "cultural industry promotion plan", upgrading the culture industry to the status of national strategic industry; in March 19, 2010, the people's Bank of China together with the Central Propaganda Department, the Ministry of finance, the Ministry of culture and other nine departments jointly issued the guide lines on financial support for culture industry development and prosperity[1], which is the first guidance document on macroscopic financial policy of supporting the development of cultural industry, and it means that the deep cooperation between the financial industry and cultural industry has been supported by the policy. Afterwards, in 2012, the Ministry of Culture issued a " cultural industry doubling plan during the period of "12th Five-Year Plan"", putting forward a plan to increase cultural industry average annual market growth rate by more than $20 \%$, which means a doubled annual market growth in 2015 compared with that in 2010. The boom of cultural industry is coming.

As a special industry, macro culture industry has its unique features, Kretsehmer and Micheal[2] summarizes four characteristics of cultural industry: (1) the product demand of the industry presents the characteristics of periodicity; (2) a large number of potential products exist; (3) special network effects appear in the consumption; (4) the quality of the products has a high degree of uncertainty. That is to say, the cultural industry has the characteristics of high investment, high risk, and high returns, which has become the cause of difficulty for the industry to get financing support.

Looking at the current financing status of domestic cultural industry, financing has become a bottleneck restricting the development of cultural industry. "The cultural industry has less tangible assets and more intangible assets", " Only the single financing channel exists " and other issues over the years have plagued domestic cultural enterprises, which is also a worldwide problem. Looking into its reasons, the key is that a majority of cultural industry assets are intangible, which are difficult to assess. Vigorously promoted in recent years by the government, the cultural industry has made considerable progress, with the investment and financing channels developed in both depth and breadth. In this process, how to reasonably measure the financial support efficiency for the culture industry in our country, so as to find out the factors which influence the efficiency of cultural industry and the ways to improve the efficiency at sight, has become a hot topic in the research of culture industry in economic field, which is also the issues that this paper concerns and discusses.

\section{REVIEW OF THE LITERATURE}

\section{A. Research on Financing and Investment of Cultural Industry}

From the beginning of the 90's of the last century, the western developed countries have increased financial support for cultural industry management, working out the relevant policies to guide the healthy development of the cultural industry. In related research, Nadiri (1993) [3] pointed out that 
the annual average rate of return in the private enterprises invested by cultural industry was between $20 \%$ and $30 \%$. The World Bank [4] pointed out in its report in 1999 that the cultural industry investment is an important component of economic investment, and is an important factor in the global economy operation. Kasi Brick Wood (2000) [5] believed that culture is the driving force for the society, and pointied out that the EU countries should review their cultural industry policies, make efforts to improve the social structure of Europe, actively implement the funding and support measures, and in the emerging field of cultural industries, such as the media industry, create employment opportunities, apply new technology to cultural activities. Choi YoungHo (2001) [6] made a study of Korean culture industry. The results show that Korean cultural industry did not only attract a lot of investment from the United States, Japan, the European Union and some other countries, but also received from the government and domestic enterprises the investment which increased by more than 35\% annually. Italy Florence Cultural Development Committee (2001) [7] believed that cultural industry policy determines the development of cultural industries, and cultural investment and financing policy is the core content of cultural industry policy. The Committee also pointed out that cultural investment and financing policy determines the culture market access. Mark Banks (2000) [8] pointed out that risk and the trust with management right play important roles in culture industry investment and financing. He also made a study of the risk control and the trust negotiation in the informal sector. Taking Manchester as an example, he explained how the risk and the trust in the local culture industry were defined and displayed.

In view of the financing problems of cultural industry, the domestic scholars also made a lot studies. Zhang Wei, Zhou Luzhu (2006) [9] proposed establishment of the investment and financing system, which "combine national and private capitals, with national capital as the guidance and private capital as the main force". Xie Luncan (2010) [10] made an analysis on the reasons for the difficulty of culture industry financing: the product in culture industry is in a form of intangible assets; the current cultural industry companies are mostly small and medium-sized ones; the development of the enterprises in cultural industry is not mature yet, and many of those enterprises have not established standardized financial systems. Yu Xiaojian, Ren Zhaozhang (2011) [11] analyzed and summarized the characteristics of financial innovation in China's cultural industry, proposed multiple enterprise copyright collection pledge loan as a new way of financing suitable for small and medium-sized enterprises. Li Huacheng (2012) [12] pointed out that the measures taken by the developed countries in Europe and America such as preferential treatment to culture industry, national treatment for international capitals, national investment and financing fund, and financial innovation initiatives, are the effective ways to solve the problem of financing difficulties for small and medium-sized enterprises. He also pointed out that Chinese cultural industry investment and financing system must be improved. Wei Pengju (2010) [13] reviewed the systematic predicament of cultural industry financing in China and the changes of the policy environment, economic environment and financial environment and their trends, interpreting with examples the direct and indirect financing of the cultural industry.

\section{B. Research on the Cultural Industry Efficiency}

In the study of the cultural industry efficiency by using DEA model, domestic scholars have already achieved some results. In 2005, by applying CCR mode, Hou Yanhong (2008) [14] analyzed the efficiency of the culture industry in every provinces in China. The results showed that the cultural industries in the 7 provinces including Guangdong and Beijing were effective. Wang Jiating and Zhang Rong (2009) [15] made a study of the culture industry efficiency in 31 provinces of China in 2004 by using three stage DEA model, and found out that after eliminating the influence of environmental and stochastic factors, they were at low levels in general. By using the BCC model under the DEA model, Ma Xuan and Zheng Shilin (2010) [16] carried out a research on 1998 - 2006 China cultural industry efficiency, and found that there were regional differences in the efficiency of cultural industry. He Liwen, Yuan Xiaoling and Deng Huimin (2012) [17] studied by using the Malmquist productivity index model the changes in the total factor productivity of the cultural industry in 31 provinces and cities in China between 2005 and 2009. The results of their study indicated that the total factor productivity of China's cultural industry showed a fluctuant growth during the period, and compared with the eastern and the central regions of China, the western part fell behind in developing culture industry. Based on the second economic census data, and by using three stage DEA model and extra efficiency DEA model, Jiang Ping and Wang Yong (2011) [18] made a study of the cultural industry efficiency in 31 provinces in China, and found out that the culture industry efficiency was greatly affected by environmental factors, and the scale inefficiency was the main reason for the low efficiency of the cultural industry. Using DEA-Malmquist method, Zheng Shilin and Ge Junyi (2012) [19] calculated the total factor productivity of China's provincial cultural industry from 1998 to 2009, and their research showed that, to deepen the cultural system reform, China should focus on improving the technical efficiency of the cultural industry.

By summarizing the existing research results, it can be found that the current studies mostly focus on measuring the cultural industry overall operating efficiency, based on the data obtained before 2009. As to the efficiency of financial support for culture industry, they rarely involved. Aiming at this deficiency, based upon the financial data of the listed companies in culture industry, and by using DEA model and Logit model, this article makes an empirical analysis. In addition, taking into consideration that 2009 to 2012 was the period while the government proposed to vigorously develop the cultural industry, this article and its related research are mainly based upon the data of recent years. 


\section{RESEARCH METHOD}

\section{A. DEA Model}

\section{1) C2R Model}

In 1978, data envelopment analysis (DEA) method was first proposed by A.Charnes, W.W.Cooper and E.Rhodes[20]. It is a nonparametric method to measure the efficiency, and is based on distance function, measurement formula of effective input technology and the Pareto theory. The core of the model is as the following: (1) if and only if the input resources increase or the other output yields decrease, the output yield will increase; (2) The input cannot be reduced, if the output does not decrease or the other input resources do not increase.

\section{2) Logit Model}

The Logit model, also known as the evaluation model and Logit regression model, is one of discrete choice models, and is the earliest as well as currently the most widely used discrete choice model. In the economic analysis, very often a choice needs to be made among several options, and these options can be represented by discrete data. For example, it can be recorded as 1 if an event occurs, and recorded as 0 if the event does not occurs. The econometric models established with the decision results as the explained variables are interpreted as discrete choice models. Among them, if there are only two choices for the explained variables, the model is known as a binary choice model; and if there are more than two choices for the explained variables, the model is then called a multiple choice model.

\section{INDICATOR、 VARIABLE AND DATA SOURCES}

\section{A. Indicator of Input and Output of DEA Model}

In this paper, the cultural industry financial support efficiency is defined as the efficiency of the activities of an enterprise, in which the enterprise puts the capital resources, which are obtained from financing activities, into production and management to promote the enterprise to achieve the efficiency of output maximization and scale merit. We choose the output orientation BC2 model in the study.

Through the principle of production method and equity method, combining with the characteristics of the listed companies in cultural industry, and drawing on the existing index selection criteria, in this article, we select the inputoutput indicators of model finally.

Input indicators selected in this paper: (1) Total assets (X1) , reflects the size and financing scale of cultural industry enterprises. It is the foundation of financial management. (2) Main business cost (X2), reflects the cost that cultural industry company engaged in main business development and production spend. Main business cost not only reflects the enterprise profit and revenue, but also illustrate the ability of using the assets by enterprises. (3) asset-liability ratio (X3), reflects the effects of capital structure on financing efficiency. It also reflects the distribution of the direct and indirect financing and its effects on the enterprise value, expressed by the formula as follows: $\mathrm{X} 3=($ total liabilities/total assets $) \times 100 \%$. (4) Quick ratio
(X4), reflects the relationship of quick assets, such as cash and those with instant liquidity, to current liabilities. It is generally believed that the reasonable value is 1 , namely enterprise's quick assets can meet all current liabilities on demand, expressed by the formula as the following: $\mathrm{X} 4=$ [(current assets- Inventory)/ current assets] $\times 100 \%$.

Output indicators selected in this paper: (1) ROE (y1), reflects the level of remuneration to raise funds. The higher the ratio is, the stronger the corporate profitability is. Expressed by the formula as follows: $y 1=$ (net income) /(total assets) $\times 100 \%$; (2) Income growth rate (y2). It is the ratio between the difference of the main business income this year and last year and the main business income last year. This index can reflect the operational efficiency of financing. The higher the ratio is, the more sustained the enterprises profitability by main business is. Expressed by the formula as follows: $y 2=[$ (main business income this year-main business income last year)/main business income last year] $\times 100 \%$;

(3) Year-on-year growth rate of the net profit attributable to shareholders of the parent company (y3). It is the ratio between the difference of the net income this year and last year and total profit last year. Net income refers to what remains after deducting the income tax in accordance with taxation laws from an enterprise's revenues. It is a comprehensive index to evaluate the profitability, management performance and solvency of enterprises, expressed by the formula as follows: net income $=[$ (total profit $) /(1$ - income tax rate $)] \times 100 \%$, hence $y 3=[($ net income this year- net income last year)/ net income last year] $\times 100 \%$.

(4) Year-on-year growth rate of the basic earnings per share ( y4) Basic EPS is calculated by dividing profit or loss attributable to ordinary equity holders of the parent entity (the numerator) by the weighted average number of ordinary shares outstanding (the denominator) during the period. It is usually used to reflect the operating results of an enterprise and measure the profitability and risk of investment of the ordinary shares, and is one of the important financial indicators that investors and other information users used to evaluate the profitability of enterprise, forecast the growth potential of enterprise and then make related economic decisions. Expressed by the formula as follows: $y 4=$ [(basic earnings per share this year- basic earnings per share last year)/ basic earnings per share last year] $\times 100 \%$.

These indicators are the indexes which measure the enterprise growth ability, and can reflect the influence of financial support on enterprise performance and enterprise scale.

\section{B. Variable Selection of of the Logit Model}

The purpose of this study is to analyze the causal relationship between the efficiency of the financial support and the investment in the industry, and explain the influence factors of cultural industry financial support efficiency. Therefore, the overall technical efficiency resulted from model DEA--BC2 is taken as the dependent variable, among which the decision unit that achieves the comprehensive technical 
efficiency is recorded as 1 , with the rest which does not achieve the comprehensive technical efficiency as 0 . Hence, it becomes a binary discrete choice, which can therefore be analyzed and solved with Logit model. The model explanatory variables are the input indicators which are set to measure DEA efficiency. The specific model is as the following:

$$
Y^{*}=\beta_{1} \cdot X_{1}+\beta_{2} \cdot X_{2}+\beta_{3} \cdot X_{3}+\epsilon_{i}
$$

The variables of the model, as shown in table 1 below.

TABLE I. LOGIT MODEL VARIABLES STATISTICAL TABLE

\begin{tabular}{l|l|l}
\hline Variable type & Variable name & Variable Meaning \\
\hline \multirow{2}{*}{$\begin{array}{l}\text { Dependent variable } \\
\text { Explaining variable }\end{array}$} & $\mathrm{Y}$ & $\begin{array}{l}\text { If the financial support } \\
\text { efficiency is achieved or } \\
\text { not., achieved 1 and not } 0 .\end{array}$ \\
\cline { 2 - 3 } & $\mathrm{X} 2$ & Total assets \\
\cline { 2 - 3 } & $\mathrm{X} 3$ & Main business cost \\
\cline { 2 - 3 } & $\epsilon_{\mathrm{i}}$ & $\begin{array}{l}\text { Asset-liability ratio } \\
\text { distribution }\end{array}$ \\
\hline \multirow{2}{*}{$\begin{array}{l}\text { Variable coefficient to } \\
\text { be estimated }\end{array}$} & $\beta_{\mathrm{i}}$ & \\
\hline
\end{tabular}

\section{Data Sources}

Considering the data availability and the listed company representativeness, this paper selected 41 listed company of cultural industry and collected financial data of them from 2009 to 2012, and took them as a representative to analyze the efficiency of financial support of cultural industry and the factors that affect the efficiency, in order to illustrate the role and importance of financial support for the development of cultural industries. The data of this study are collected from the Tai'an CSMAR database. Analysis software used by the DEA model is DEAP2.1 and Analysis software used by the Logit model is Eviews7.0.

\section{EMPIRICAL ANALYSIS ON THE RESULTS}

\section{A. DEA Analysis of the Cultural Industry Financial Support Efficiency}

firstly, the comprehensive technical efficiency, pure technical efficiency and scale efficiency of the sample companies from 2009 to 2012, increased year by year, by $28.2 \%, 15.1 \%$ and $11.9 \%$ respectively, which indicates that the culture industry enterprises'capabilities of financing from financial markets to support the implementation of the culture industry value maximization have become increasingly strong. Nevertheless, that the average overall efficiency data of each year are respectively $55.03 \%, 60.49 \%, 64.66 \%, 70.58 \%$ shows the cultural industry overall financial support efficiency level is still unsatisfactory, having room to improve yet.

Secondly, among them, the average pure technical efficiency of each year is higher than the average scale efficiency, which means the main reason for the sample companies' technology inefficiency is their average scale inefficiency, and under the condition that current techniques and existing ways of getting financial support remain unchanged, as a whole, the size of the financing of cultural industry also has a further room to improve.

Finally, among all the companies, such companies as Music Network, Huayi Brothers and Blue Cursor rank at the forefront of the industry in the financing efficiency evaluation, with higher comprehensive technical efficiency, pure technical efficiency and scale efficiency. While the finance support efficiency indicators of those companies as Earth media, Era Publishing, Radio and Television Network are not ideal. One reason is their geographical positions. With the cluster effect of cultural industry, the companies located in Beijing, Hunan and other cultural and media industry concentrated regions are relatively easy to obtain financial support, but the efficiency of the financial support to those in rural areas is relatively low. So, we should reinforce the development of the industrial chain, expanding the cultural industry cluster effect.

\section{B. Analysis of Logit Model}

In 2009 and 2010, since the $\mathrm{Z}$ test value adjoint probability Prob. of the total assets (X1) and the asset-liability ratio (X3), which are the explanatory variables, are both less than the significant level 0.05, they have significant influence on the dependent variables. On the other hand, another explanatory variable, main business costs (X2), does not have significant influence on the financial support efficiency. The model's goodness-of-fit test is assumed originally to be complete fit. Under the confidence level 0.05 , the adjoint probabilities of Hosmer-Lemeshow test and Andrews test are both within the presumed acceptable area, which means the fitting effect of the model as a whole is satisfactory. Since the coefficients of $\mathrm{X} 1$ and $\mathrm{X} 3$ are positive and negative respectively, expanding its asset size is therefore considered to be conducive to the financing support of cultural industry and realizing the maximum value of the industry, when the other conditions remain unchanged in 2009 and 2010. Besides, indirect financing is considered to have a negative impact on obtaining financial support for enterprises.

Model fitting results for 2011 and 2012 show that $\mathrm{Z}$ test value adjoint probability values of variables $\mathrm{X} 1, \mathrm{X} 2, \mathrm{X} 3$ are all less than the significant level of 0.05 , and all have significant effects on the dependent variable. The model's goodness-of-fit test is assumed originally to be complete fit. Under the confidence level 0.05 , the adjoint probabilities of HosmerLemeshow test and Andrews test are both within the presumed acceptable area, which means the fitting effect of the model as a whole is satisfactory. Since the coefficients of X1 and X3 are positive and negative respectively, expanding its asset size and improving the ability of using the enterprise assets are therefore considered to be conducive to the financing support of cultural industry, when the other conditions remain unchanged in 2011 and 2012. Indirect financing, however, still has a negative impact on obtaining financial support for enterprises.

To sum up, from 2009 to 2012, the total assets and the efficiency of the cultural industry financial support were positively correlated, i.e. expanding the scales or increasing the capitals were in favor of helping enterprises to obtain financial supports. While the result that the impacts of the 
main business cost on the enterprise financing efficiency changed from zero to positive means the scale was the main factor affecting the financing efficiency at the beginning, and with the development of the industry and the expansion of the enterprises' scales, the ability of improving asset utilization played an important role in improving the financing efficiency. It also shows that the culture industry was in a process of steady development during those years. Besides, the result indicates as well that indirect financing always had negative effects on the culture industry financing, which is attributed to the fact that due to its being one of emergent industries and its own unique "high investment, high risk, less tangible assets" features, it is not easy for culture industry to obtain indirect financing.

\section{CONCLUSION}

Taking all the results of DEA model and Logit model into consideration, regarding the cultural industry financial support efficiency and affecting factors, we can draw following conclusions:

From 2009 to 2012, the average comprehensive technical efficiency level of financial support that cultural industry acquired is $55.03 \%, 60.49 \%, 64.66 \%$ and $70.58 \%$ respectively. It shows that the financing efficiency of cultural industry in general has been increasing, but the levels are still fairly low, and there is room to rise.

In the selected sample companies, the companies of comprehensive technical inefficiency account for a large proportion. Among them the financing scale of company becomes the key factor affecting the efficiency of financing. Those companies, which have various ideal indexes of financing efficiency, are the companies with larger scales.

The analysis of Logit model of the factor affecting cultural industry financial support efficiency showed that expanding the scale has been good for enterprises to acquire financial support in 2009 to 2012. With development and maturation of the industry, the ability of using assets becomes the key factor to improve financing efficiency of enterprises. Furthermore, cultural industries, because of its high input, high risk, are difficult to get access to indirect financing. Therefore, there is a negative correlation between indirect financing and efficiency of financial support of cultural industry.

\section{ACKNOWLEDGMENT}

The paper thanks Beijing natural science foundation project: 2013 Beijing low-carbon investment and financing mode and operation simulation (project number: 9132001) ; 2011 annual national social science fund major projects: emerging technology analysis theory method and industrial innovation research(project number: 11 \& ZD140); Beijing philosophy and social sciences planning project in 2011, the project name: Beijing modern manufacturing listed company credit risk research(project number: 11JGB029).

\section{REFERENCES}

[1] China Government, About the financial support the development of the cultural industry revitalization and prosperity of the guidance, http://www.cnci.gov.cn/specail/cncisp/zt20100325/

[2] Kretsehmer, Michacel. Interesting returns and social contagion in cultural industries. British Journal of Management, Special Issue.1999: 22-23.

[3] Nadiri.M.I. Innovations and Technological Spillovers, Working Paper NO.4423, Cambridge, MA: National Bureua of Economic Research, 1993: 183-249.

[4] The world bank. World culture industry development trend(in Chinese), World bank industry development report, 2005, 13-100.

[5] Kathy wood, Culture industry investment and development (in Chinese), Shanghai: Shanghai translation publishing house, 2005:193-194.

[6] Choi YoungHo, South Korean culture industry trends (in Chinese), Shanghai: Shanghai translation publishing house, 2005:89-90.

[7] Fiorentina city culture development center, Fiorentina cultural practices (in Chinese), Beijing: China economic publishing house, 2004.

[8] Mark Banks, Andy Lovatt, Justin O'Connor, Carlo Raffo Risk and trust in the cultural industries, Geoforum, 2000(31):453-464.

[9] Zhang wei, Zhou Luzhu, China's culture industry investment and financing problems and countermeasures(in Chinese), Journal of modern communications, 2006 (4): 106-112.

[10] Xie Luncan, Culture industry financing analysis of the status of the perspective and countermeasures(in Chinese), Journal of tongji university, 2010 (10): 40 to 44.

[11] Yu Xiaojian, Ren Zhaozhang, Financial innovation analysis of cultural industry in China(in Chinese), Journal of Shanghai's financial, 2011 (6): 105-108.

[12] Li Huacheng, Europe and the United States and its enlightenment to our country culture industry investment and financing system (in Chinese), Journal of scientific technological progress and countermeasures 2012 (4): 107-112.

[13] Wei Pengju, China's culture industry financing environment and the mode analysis(in Chinese), Journal of tongji university, 2010 (10): 46-50.

[14] Hou Yanhong, Culture industry investment performance evaluation research (in Chinese dissertation), Tianjin: tianjin university of technology, 2008, 31-36.

[15] Wang Jiating, Zhang Rong, Based on the three-stage DEA model research input-output efficiency of cultural industry in 31 provinces in China(in Chinese), Journal of China soft science, 2009 (9): 75-82.

[16] Ma Xuan, Zheng Shilin, China's culture industry research were summarized and prospect(in Chinese), Journal of economics, 2010 (3): $3-6$.

[17] He Liwen, Yuan Xiaoling, Deng Minhui, China's culture industry total factor productivity change and regional difference analysis(in Chinese), Journal of economic issues to explore, 2012 (9): 71-77.

[18] Jiang ping, Wang yong, The whole caliber input-output efficiency of China's culture industry research (in Chinese), The number of economic and technological research, 2011 (12): 69-81.

[19] Zheng Shilin, Ge Junyi, The reform of cultural system and cultural industrial total factor productivity growth, Journal of China soft science, 2012 (10): 48-58.

[20] A.Charnes,W.W.Coper,E.Rhodes, Measuring the Efficiency of Decision Making Units, European Journal of Operational Research - EJOR , vol. 2, no. 6 , pp. 429-444, 1978 .. 